\title{
Article \\ ADC-Based Stratification of Molecular Glioma Subtypes Using High b-Value Diffusion-Weighted Imaging
}

\author{
Nils C. Nuessle ${ }^{1, *}$, Felix Behling ${ }^{2,3}{ }^{\oplus}$, Ghazaleh Tabatabai ${ }^{3}$, Salvador Castaneda Vega ${ }^{4}$, Jens Schittenhelm ${ }^{5}($, \\ Ulrike Ernemann ${ }^{1}$, Uwe Klose ${ }^{1}$ (D) and Johann-Martin Hempel ${ }^{1}$
}

1 Department of Neuroradiology, University Hospital Tübingen, Eberhard Karls University, 72076 Tübingen, Germany; ulrike.ernemann@med.uni-tuebingen.de (U.E.); uwe.klose@med.uni-tuebingen.de (U.K.); johann-martin.hempel@med.uni-tuebingen.de (J.-M.H.)

2 Department of Neurosurgery, University Hospital Tübingen, Eberhard Karls University, 72076 Tübingen, Germany; felix.behling@med.uni-tuebingen.de

3 Departments of Neurology and Interdisciplinary Neuro-Oncology, University Hospital Tübingen, Hertie Institute for Clinical Brain Research, Eberhard Karls University, 72076 Tübingen, Germany; ghazaleh.tabatabai@med.uni-tuebingen.de

4 Werner Siemens Imaging Center, Department of Preclinical Imaging and Radiopharmacy, University Hospital Tübingen, Eberhard Karls University, 72076 Tübingen, Germany; salvador.castaneda@med.uni-tuebingen.de

5 Department of Pathology and Neuropathology, University Hospital Tübingen, Institute of Neuropathology, Eberhard Karls University, 72076 Tübingen, Germany; jens.schittenhelm@med.uni-tuebingen.de

* Correspondence: nils.nuessle@hotmail.com

check for updates

Citation: Nuessle, N.C.; Behling, F.; Tabatabai, G.; Castaneda Vega, S.; Schittenhelm, J.; Ernemann, U.; Klose, U.; Hempel, J.-M. ADC-Based Stratification of Molecular Glioma Subtypes Using High b-Value Diffusion-Weighted Imaging. J. Clin. Med. 2021, 10, 3451. https://doi.org/ $10.3390 /$ jcm10163451

Academic Editors: Cornelia Brendle and Georgios Tsivgoulis

Received: 8 June 2021

Accepted: 2 August 2021

Published: 4 August 2021

Publisher's Note: MDPI stays neutral with regard to jurisdictional claims in published maps and institutional affiliations.

Copyright: (c) 2021 by the authors. Licensee MDPI, Basel, Switzerland. This article is an open access article distributed under the terms and conditions of the Creative Commons Attribution (CC BY) license (https:// creativecommons.org/licenses/by/ $4.0 /)$.
Abstract: Purpose: To investigate the diagnostic performance of in vivo ADC-based stratification of integrated molecular glioma grades. Materials and methods: Ninety-seven patients with histopathologically confirmed glioma were evaluated retrospectively. All patients underwent pre-interventional MRI-examination including diffusion-weighted imaging (DWI) with implemented b-values of 500, 1000, 1500, 2000, and $2500 \mathrm{~s} / \mathrm{mm}^{2}$. Apparent Diffusion Coefficient (ADC), Mean Kurtosis (MK), and Mean Diffusivity (MD) maps were generated. The average values were compared among the molecular glioma subgroups of IDH-mutant and IDH-wildtype astrocytoma, and 1p/19q-codeleted oligodendroglioma. One-way ANOVA with post-hoc Games-Howell correction compared average $\mathrm{ADC}, \mathrm{MD}$, and MK values between molecular glioma groups. A Receiver Operating Characteristic (ROC) analysis determined the area under the curve (AUC). Results: Two b-value-dependent ADCbased evaluations presented statistically significant differences between the three molecular glioma sub-groups $(p<0.001$, respectively). Conclusions: High-b-value ADC from preoperative DWI may be used to stratify integrated molecular glioma subgroups and save time compared to diffusion kurtosis imaging. Higher b-values of up to $2500 \mathrm{~s} / \mathrm{mm}^{2}$ may present an important step towards increasing diagnostic accuracy compared to standard DWI protocol.

Keywords: diffusion-weighted imaging; DWI; diffusion kurtosis imaging; DKI; ADC; glioma

\section{Introduction}

Gliomas are one of the most common primary central nervous system tumors and are, in most cases, associated with poor overall survival [1]. Treatment options include surgical resection, chemotherapy, and radiation therapy, depending on the histopathological entity $[1,2]$.

Unfortunately, the distinction between different glioma subtypes with sufficient sensitivity and specificity remains challenging in preoperative settings and imaging. A reliable pre-interventional glioma stratification based on the expected molecular glioma profile may impact therapeutic options, the extent of planned surgical resection, and prognosis [3-5].

Various models have been proposed in previous reports to distinguish non-invasively different tumor entities using MRI. ADC-map-based tumor evaluation from diffusionweighted imaging (DWI) seems to be a promising means of differentiation [6,7]. 
Standardized MRI protocols for glioma patients have been proposed. They are used in most centers, but standardized evaluation methods for non-invasive grading and follow-up have not yet been implemented in the clinical workflow [8,9].

In the past, diffusion kurtosis imaging (DKI) and high-b-value DWI showed great potential and good diagnostic capability. For DKI, several multidirectional b-values are needed. They are correlated with an extended acquisition time and complex postprocessing $[10,11]$.

However, the calculation of ADC maps from DWI is a fast and straightforward procedure that has already shown the potential for distinguishing high-grade from lowgrade glioma according to the previous 2007 World Health Organization Classification of Tumors of the Central Nervous System (2007 CNS WHO) [6]. Therefore, this study aims to evaluate high-b-value ADC-based tumor classification's diagnostic performance and compare it with DKI-based tumor stratification according to integrated glioma grades.

\section{Materials and Methods}

\subsection{Study Types and Ethics}

This study is a retrospective analysis of prospective data acquired in a single-center, non-randomized trial, approved by the local institutional review board of the University Hospital Tuebingen (Ref. No. 727/2017BO2). The trial was conducted based on the International Conference on Harmonization: Good Clinical Practice guidelines and according to the revised version of the declaration of Helsinki. All patients provided written informed consent for the imaging surveys and the subsequent use of images for scientific and research purposes.

\subsection{Patient Selection and Stratification}

The study cohort was selected from 130 patients suspected to have a primary CNS tumor between October 2012 and September 2017. Seventy-seven of the patients had been assessed previously with diffusion kurtosis imaging [12]. All patients received preoperative cerebral MR scans within two weeks of diagnosis, and none of them were receiving steroid therapy at the time of analysis. Thirty-three patients were removed from the study collective because of low image quality (e.g., moving artifacts, early stop to the MR examination), non-existing histopathological sampling, infectious diseases, gliosis, or minimal tumor volume. The final study cohort comprised 97 patients with a mean age of $51.6 \pm 15.3$ years (see Figure 1).

\subsection{Glioma Classification}

The final glioma classification was based on the current 2016 CNS WHO criteria [4] and included histopathological and molecular data.

The IDH mutation status was assessed by immunohistochemistry with a mutationspecific IDH1 R132H antibody [13]. This was followed by Sanger sequencing of the negative cases to detect any non-canonical IDH1/2 mutations [14]. Nuclear ATRX status in tumor cells was determined by immunohistochemistry, as described previously [15]. A synthetic high-resolution microsatellite PCR gel was used to study chromosome $1 \mathrm{p} / 19 \mathrm{q} \mathrm{LOH}$ in all tumors with an oligodendroglial component [16].

In the integrated approach, the combination of the loss of ATRX expression and the presence of IDH1/2 mutation characterized IDH-mutant (IDH-mut) astrocytoma, including its most aggressive histological subtype of Astrocytoma, IDH-mutant, WHO grade 4 according to the cIMPACT-NOW update 5 [11]. These tumors were formerly designated as Glioblastoma, IDH mutant, WHO grade IV. Grade IV tumors with IDH wild-type status and retained ATRX expression are primary Glioblastomas (IDH-wt). Oligodendrogliomas were defined by synchronous $1 \mathrm{p} / 19 \mathrm{q}$ loss of heterozygosity and IDH1/2 mutation (1p/19q-Codel Oligodendroglioma), and they are typically associated with maintained ATRX expression (see Figure 1) [17-20]. 


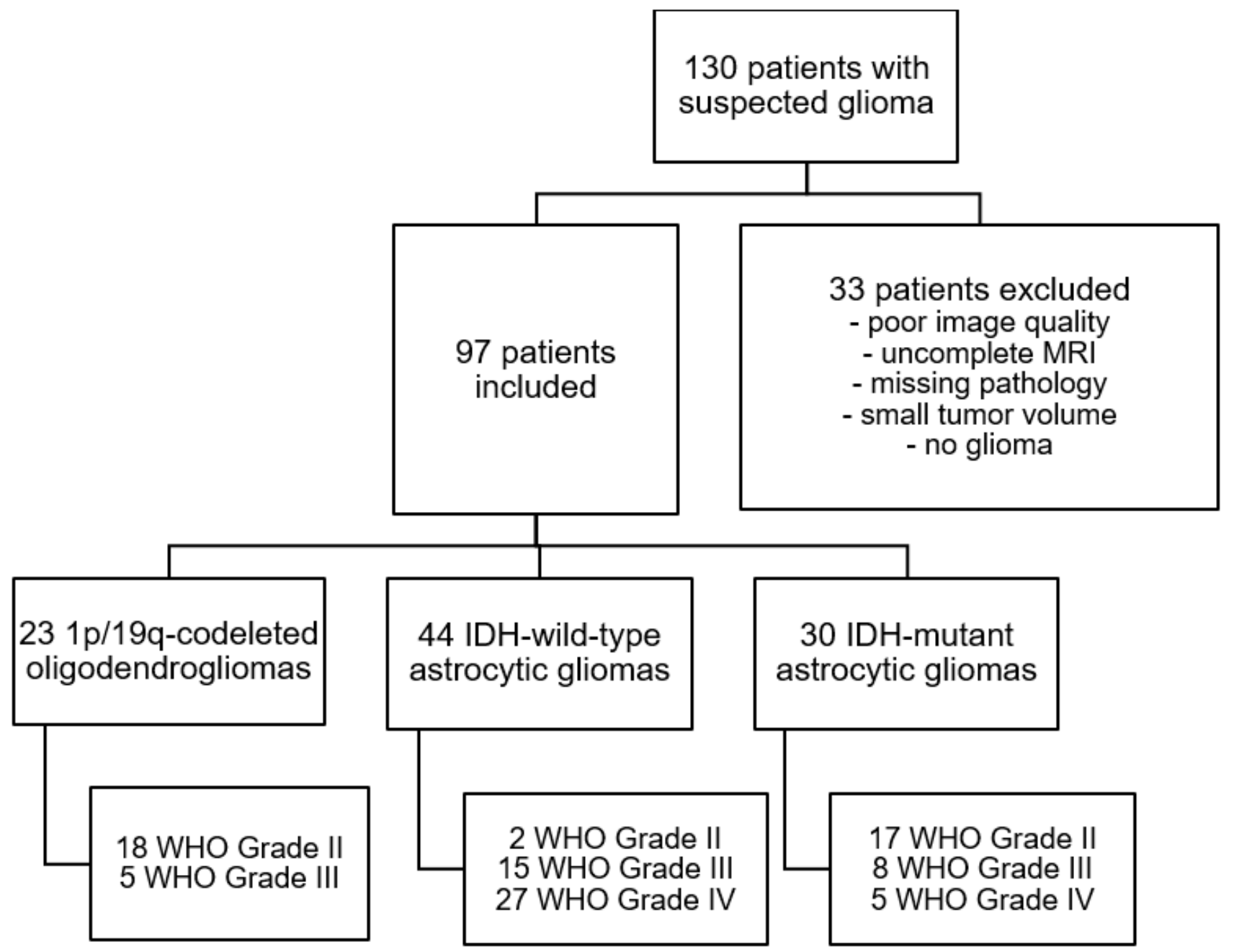

Figure 1. Patient selection algorithm according to the STROBE guidelines.

The final groups consisted of 23 1p/19q-Codel Oligodendrogliomas, 44 IDH wild-type Astrozytomas, and 30 IDH-mutant Astrozytomas (17 WHO Grade II, 8 WHO Grade III, 5 WHO Grade IV).

\subsection{MR Imaging}

MRI was performed using a 3.0 T MRI scanner (Biograph mMR, Siemens Healthineers, Erlangen, Germany). Imaging was carried out using a transversal 2D-encoded T2-weighted fluid-attenuated inversion recovery (FLAIR) sequence (TR/TE, 9000/87 ms; inversion time, $2500 \mathrm{~ms}$; 36 slices; slice thickness, $4.0 \mathrm{~mm}$ ) and a sagittal 3D-encoded isotropic magnetization prepared rapid acquisition gradient echo (MPRAGE) sequence (TR/TE, 1900/2.4 ms; TI, 900 ms; 124 partitions; slice thickness, $1.0 \mathrm{~mm}$ ) before and after contrast medium administration $(0.1 \mathrm{~mL} / \mathrm{kg}$ body weight gadobutrol) were part of the conventional MR examination protocol.

The Spin-echo echo-planar imaging DWI sequence used b values of 0, 500, 1000, 1500,2000 , and $2500 \mathrm{~s} / \mathrm{mm}^{2}$ with encoding in 6 directions. The other imaging parameters were as follows: TR $5900 \mathrm{~ms}$, TE $95 \mathrm{~ms}$; field of view, $250 \times 250 \mathrm{~mm}^{2}$; matrix $128 \times 128$; 25 slices; slice thickness, $5 \mathrm{~mm}$; bandwidth, $965 \mathrm{~Hz} /$ pixel; parallel imaging with a sensitivity encoding factor of two in the anteroposterior direction.

\subsection{Image Post-Processing}

Imaging post-processing used Matlab (MatLab 9.2, Natwick, MA, USA). All six measured directions of the six b-values in DWI were averaged. 
Five different sets of apparent diffusion coefficient (ADC) maps were calculated using the $b$-value of $0 \mathrm{~s} / \mathrm{mm}^{2}$ as a reference baseline value ( $\mathrm{B}_{0} \mathrm{ADC}$ maps) and one other $\mathrm{b}$-value $\left(\mathrm{B}_{0 / 500} \mathrm{ADC}, \mathrm{B}_{0 / 1000} \mathrm{ADC}, \mathrm{B}_{0 / 1500} \mathrm{ADC}, \mathrm{B}_{0 / 2000} \mathrm{ADC}\right.$, and $\left.\mathrm{B}_{0 / 2500} \mathrm{ADC}\right)$.

Another four sets of ADC-maps were calculated with a baseline b-value of $500 \mathrm{~s} / \mathrm{mm}^{2}$ ( $\mathrm{B}_{500} \mathrm{ADC}$ maps) and one other b-value (B500/1000 ADC, $\mathrm{B}_{500 / 1500} \mathrm{ADC}, \mathrm{B}_{500 / 2000} \mathrm{ADC}$, and $\mathrm{B}_{500 / 2500} \mathrm{ADC}$ ) to avoid perfusion-based influence on images and perfusion-artifacts.

Additionally, mean kurtosis (MK) and mean diffusivity (MD) maps were calculated, one time using all b-values, including $0 \mathrm{~s} / \mathrm{mm}^{2}\left(\mathrm{MK}_{0}\right.$ and $\left.\mathrm{MD}_{0}\right)$, and a second time excluding the $\mathrm{b}$-value of $0 \mathrm{~s} / \mathrm{mm}^{2}\left(\mathrm{MK}_{500}\right.$ and $\left.\mathrm{MD}_{500}\right)$, as described in previous studies, to compare them to the new procedure of ADC-map-based evaluation $[10,11,21]$.

In total, 14 different sets of $\operatorname{ADC}(n=9), \operatorname{MK}(n=2)$, and $\operatorname{MD}(n=2)$ parametric maps were generated for further analysis.

Subsequently, all maps were registered and interpolated to the matrix of the FLAIR images.

The volumes of interest (VOIs) were manually delineated on the FLAIR sequences based on T2 signal alterations. The VOIs were delineated around the entire tumor volume on multiple slices to minimize sampling bias. Tumor necrosis and surrounding edema and great vessels were excluded from the VOIs.

The VOIs were then transferred from the FLAIR images to the ADC, MK, and MD maps. Average ADC, MK, and MD values, as well as standard deviation, were calculated for each tumor region. This process is visualized in Figure 2. Subsequently, statistical differences were calculated, and a receiver operating characteristics (ROC) analysis was performed.
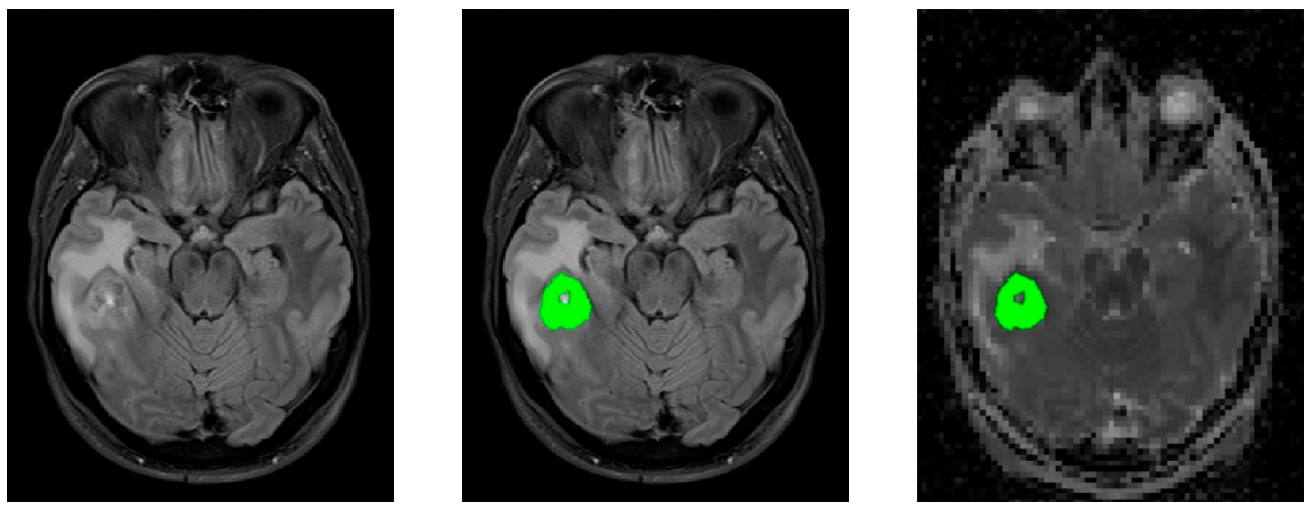

Figure 2. FLAIR and DW Images of histopathologically confirmed IDH-wt Glioblastoma-patient: unmodified FLAIR (left); FLAIR with drawn-in tumor region (green); excluding central necrosis and surrounding edema (middle); ADC map from DWI, fitted to the matrix of the FLAIR images, with transferred tumor region (right).

\section{Results}

\section{1. $A D C$}

Average ADC (avADC) values were significantly higher in IDH-mut gliomas than in oligodendrogliomas and IDH-wt gliomas. AvADC values in oligodendrogliomas were significantly higher than in IDH-wt gliomas. These effects were found in all comparisons and are presented in Table 1.

Higher b-values provided higher levels of significant differences between the three glioma-subtypes, even if the signal-to-noise ratio was higher for low b-values.

In the five $\mathrm{B}_{0} \mathrm{ADC}$ maps, differentiation between the three glioma subtypes was at the highest significance level when using the highest b-value of $2500 \mathrm{~s} / \mathrm{mm}^{2}$ (see Table 2).

The avADC values based on the four additional $B_{500}$ ADC maps showed the same relations as the $\mathrm{B}_{0} \mathrm{ADC}$-maps between the three tumor groups (see Table 3 ). 
Table 1. $B_{0}$-avADC values of the three glioma subgroups $\left(10^{-3} \times \mathrm{mm}^{2} / \mathrm{s}\right)$.

\begin{tabular}{cccc}
\hline & $\begin{array}{c}\text { IDH-mut Astrocytic } \\
\text { Gliomas }\end{array}$ & $\begin{array}{c}\text { 1p/19q-Codel } \\
\text { Oligodendroglioma }\end{array}$ & $\begin{array}{c}\text { IDH-wt Astrocytic } \\
\text { Gliomas }\end{array}$ \\
\hline $\mathrm{B}_{0 / 500} \mathrm{ADC}$ & $1.59 \pm 0.26$ & $1.42 \pm 0.27$ & $1.19 \pm 0.2$ \\
$\mathrm{~B}_{0 / 1000} \mathrm{ADC}$ & $1.5 \pm 0.27$ & $1.32 \pm 0.23$ & $1.09 \pm 0.19$ \\
$\mathrm{~B}_{0 / 1500} \mathrm{ADC}$ & $1.4 \pm 0.26$ & $1.21 \pm 0.19$ & $1.00 \pm 0.18$ \\
$\mathrm{~B}_{0 / 2000} \mathrm{ADC}$ & $1.29 \pm 0.24$ & $1.11 \pm 0.15$ & $0.92 \pm 0.16$ \\
$\mathrm{~B}_{0 / 2500} \mathrm{ADC}$ & $1.18 \pm 0.22$ & $1.01 \pm 0.12$ & $0.84 \pm 0.14$ \\
\hline
\end{tabular}

Table 2. Statistical differences ( $p$-values) and AUC from ROC analysis of the three glioma subgroups for $\mathrm{B}_{0} \mathrm{ADC}$-evaluation: AUC, area under the curve; ROC, receiver operation characteristic; MK, mean kurtosis; MD, mean diffusivity.

\begin{tabular}{|c|c|c|c|c|c|c|}
\hline & $\begin{array}{l}\text { IDH-mut vs. } \\
\text { IDH-wt } \\
\text { Astrocytic } \\
\text { Gliomas }\end{array}$ & $\begin{array}{l}\text { IDH-mut vs. } \\
\text { IDH-wt Astrocytic } \\
\text { Gliomas; AUC }\end{array}$ & $\begin{array}{c}\text { 1p/19q-Codel } \\
\text { Oligodendroglioma } \\
\text { vs. IDH-wt Astrocytic } \\
\text { Gliomas }\end{array}$ & $\begin{array}{l}\text { 1p/19q-Codel } \\
\text { Oligodendroglioma } \\
\text { vs. IDH-wt Astrocytic } \\
\text { Gliomas; AUC }\end{array}$ & $\begin{array}{c}\text { 1p/19q-Codel } \\
\text { Oligodendroglioma } \\
\text { vs. IDH-mut } \\
\text { Astrocytic Gliomas }\end{array}$ & $\begin{array}{l}\text { 1p/19q-Codel } \\
\text { Oligodendroglioma vs. } \\
\text { IDH-mut Astrocytic } \\
\text { Gliomas; AUC }\end{array}$ \\
\hline $\mathrm{B}_{0 / 500} \mathrm{ADC}$ & $<0.0001$ & 0.874 & 0.002 & 0.778 & 0.08 & 0.696 \\
\hline $\mathrm{B}_{0 / 1000} \mathrm{ADC}$ & $<0.0001$ & 0.883 & $<0.001$ & 0.784 & 0.03 & 0.699 \\
\hline $\mathrm{B}_{0 / 1500} \mathrm{ADC}$ & $<0.0001$ & 0.879 & 0.0001 & 0.789 & 0.01 & 0.736 \\
\hline $\mathrm{B}_{0 / 2000} \mathrm{ADC}$ & $<0.0001$ & 0.883 & $<0.0001$ & 0.795 & 0.005 & 0.747 \\
\hline $\mathrm{B}_{0 / 2500} \mathrm{ADC}$ & $<0.0001$ & 0.888 & $<0.0001$ & 0.799 & 0.003 & 0.751 \\
\hline
\end{tabular}

Table 3. $B_{500}$-average ADC values of the three glioma subgroups $\left(10^{-3} \times \mathrm{mm}^{2} / \mathrm{s}\right)$.

\begin{tabular}{cccc}
\hline & $\begin{array}{c}\text { IDH-mut vs. IDH-wt } \\
\text { Astrocytic Gliomas }\end{array}$ & $\begin{array}{c}\text { 1p/19q-Codel } \\
\text { Oligodendroglioma vs. IDH-wt } \\
\text { Astrocytic Gliomas }\end{array}$ & $\begin{array}{c}\text { 1p/19q-Codel } \\
\text { Oligodendroglioma vs. } \\
\text { IDH-mut Astrocytic Gliomas }\end{array}$ \\
\hline $\mathrm{B}_{500 / 1000} \mathrm{ADC}$ & $1.41 \pm 0.28$ & $1.21 \pm 0.19$ & $0.99 \pm 0.18$ \\
$\mathrm{~B}_{500 / 1500} \mathrm{ADC}$ & $1.31 \pm 0.27$ & $1.10 \pm 0.15$ & $0.90 \pm 0.17$ \\
$\mathrm{~B}_{500 / 2000} \mathrm{ADC}$ & $1.19 \pm 0.24$ & $1.00 \pm 0.12$ & $0.83 \pm 0.15$ \\
$\mathrm{~B}_{500 / 2500} \mathrm{ADC}$ & $1.07 \pm 0.21$ & $0.91 \pm 0.10$ & $0.76 \pm 0.13$ \\
\hline
\end{tabular}

Compared with the avADC values based on $\mathrm{B}_{0} \mathrm{ADC}$ maps, they showed a much better correlations with the tumor entities in lower b-values and slightly better results in terms of their high b-values such as $2500 \mathrm{~s} / \mathrm{mm}^{2}$ (see Table 4).

Table 4. Statistical differences ( $p$-values) and AUC from ROC analysis of the three glioma subgroups for $\mathrm{B}_{0} \mathrm{ADC}$ evaluation: AUC, area under the curve; ROC, receiver operation characteristic; MK, mean kurtosis; $M D$, mean diffusivity.

\begin{tabular}{|c|c|c|c|c|c|c|}
\hline & $\begin{array}{l}\text { IDH-mut vs. } \\
\text { IDH-wt } \\
\text { Astrocytic } \\
\text { Gliomas }\end{array}$ & $\begin{array}{l}\text { IDH-mut vs. } \\
\text { IDH-wt Astrocytic } \\
\text { Gliomas; AUC }\end{array}$ & $\begin{array}{l}\text { 1p/19q-Codel } \\
\text { Oligodendroglioma } \\
\text { vs. IDH-wt Astrocytic } \\
\text { Gliomas }\end{array}$ & $\begin{array}{l}\text { 1p/19q-Codel } \\
\text { Oligodendroglioma } \\
\text { vs. IDH-wt Astrocytic } \\
\text { Gliomas; AUC }\end{array}$ & $\begin{array}{c}\text { 1p/19q-Codel } \\
\text { Oligodendroglioma } \\
\text { vs. IDH-mut } \\
\text { Astrocytic Gliomas }\end{array}$ & $\begin{array}{l}\text { 1p/19q-Codel } \\
\text { Oligodendroglioma vs. } \\
\text { IDH-mut Astrocytic } \\
\text { Gliomas; AUC }\end{array}$ \\
\hline $\mathrm{B}_{500 / 1000} \mathrm{ADC}$ & $<0.0001$ & 0.878 & $<0.0001$ & 0.798 & 0.01 & 0.723 \\
\hline $\mathrm{B}_{500 / 1500} \mathrm{ADC}$ & $<0.0001$ & 0.880 & $<0.0001$ & 0.795 & 0.003 & 0.746 \\
\hline $\mathrm{B}_{500 / 2000} \mathrm{ADC}$ & $<0.0001$ & 0.883 & $<0.0001$ & 0.806 & 0.002 & 0.751 \\
\hline $\mathrm{B}_{500 / 2500} \mathrm{ADC}$ & $<0.0001$ & 0.884 & $<0.0001$ & 0.808 & 0.001 & 0.751 \\
\hline
\end{tabular}

The distribution of avADC values can be seen in Figure A1.

\section{2. $M K$}

MK-map-based evaluation of the tumor regions revealed the highest level of significant differences between the different glioma subtypes.

All three groups showed highly significant differences when including all measured b-values (see Tables 5 and 6).

The distribution of MK values of each patient in one MK map can be seen in Figure A2. 
Table 5. MK and MD values of the three glioma subgroups (MK metrics are dimensionless, MD in $\left.10^{-6} \times \mathrm{mm}^{2} / \mathrm{s}\right)$.

\begin{tabular}{cccc}
\hline & $\begin{array}{c}\text { IDH-mut Astrocytic } \\
\text { Gliomas }\end{array}$ & $\begin{array}{c}\text { 1p/19q-Codel } \\
\text { Oligodendroglioma }\end{array}$ & $\begin{array}{c}\text { IDH-wt Astrocytic } \\
\text { Gliomas }\end{array}$ \\
\hline $\mathrm{MK}_{0}$ & $446.1 \pm 109$ & $552.8 \pm 88$ & $705.1 \pm 145$ \\
$\mathrm{MK}_{500}$ & $593.8 \pm 121$ & $694.4 \pm 114$ & $825.3 \pm 145$ \\
$\mathrm{MD}_{0}$ & $1681 \pm 293$ & $1504 \pm 313$ & $1224 \pm 257$ \\
$\mathrm{MD}_{500}$ & $1518 \pm 314$ & $1288 \pm 227$ & $1029 \pm 224$ \\
\hline
\end{tabular}

Table 6. Statistical differences ( $p$-values) and AUC from ROC analysis of the three glioma subgroups for MK and MD evaluation: AUC, area under the curve; ROC, receiver operation characteristic; MK, mean kurtosis; MD, mean diffusivity.

\begin{tabular}{|c|c|c|c|c|c|c|}
\hline & $\begin{array}{l}\text { IDH-mut vs. } \\
\text { IDH-wt } \\
\text { Astrocytic } \\
\text { Gliomas }\end{array}$ & $\begin{array}{l}\text { IDH-mut vs. } \\
\text { IDH-wt Astrocytic } \\
\text { Gliomas; AUC }\end{array}$ & $\begin{array}{l}\text { 1p/19q-Codel } \\
\text { Oligodendroglioma } \\
\text { vs. IDH-wt Astrocytic } \\
\text { Gliomas }\end{array}$ & $\begin{array}{l}\text { 1p/19q-Codel } \\
\text { Oligodendroglioma } \\
\text { vs. IDH-wt Astrocytic } \\
\text { Gliomas; AUC }\end{array}$ & $\begin{array}{l}\text { 1p/19q-Codel } \\
\text { Oligodendroglioma } \\
\text { vs. IDH-mut } \\
\text { Astrocytic Gliomas }\end{array}$ & $\begin{array}{l}\text { 1p/19q-Codel } \\
\text { Oligodendroglioma vs. } \\
\text { IDH-mut Astrocytic } \\
\text { Gliomas; AUC }\end{array}$ \\
\hline $\mathrm{MK}_{0}$ & $<0.0001$ & 0.922 & $<0.0001$ & 0.818 & $<0.001$ & 0.799 \\
\hline $\mathrm{MK}_{500}$ & $<0.0001$ & 0.869 & $<0.001$ & 0.755 & 0.009 & 0.744 \\
\hline $\mathrm{MD}_{0}$ & $<0.0001$ & 0.887 & 0.002 & 0.781 & 0.1 & 0.696 \\
\hline $\mathrm{MD}_{500}$ & $<0.0001$ & 0.887 & $<0.001$ & 0.790 & $<0.01$ & 0.714 \\
\hline
\end{tabular}

\section{3. $M D$}

The evaluation of MD maps displayed differences between the three groups, as well. Calculation of the MD maps excluding the b-value of $0 \mathrm{~s} / \mathrm{mm}^{2}$ resulted in better discrimination, as displayed in Table 6.

Nevertheless, the level of significance was lower than in the two other evaluation procedures described.

The comparison between $1 \mathrm{p} / 19 \mathrm{q}$-Codel Oligodendroglioma and IDH-wt astrocytic gliomas in the MD-map, including the b-value of $0 \mathrm{~s} / \mathrm{mm}^{2}$, showed no significant difference (see Table 6).

\section{Discussion}

The aim of this study was to evaluate a high-b-value ADC-based tumor classification's diagnostic performance and compare it with DKI-based tumor stratification according to the latest integrated glioma grades. In contrast to previous studies, not only were multiple b-value-dependent MK and MD analyses used, but a two b-value-dependent ADC-mapbased method was also performed $[5,12,22,23]$. High-b-value ADC from preoperative DWI may be used to stratify molecular glioma subgroups and save time compared to DKI. Higher b-values up to $2500 \mathrm{~s} / \mathrm{mm}^{2}$ may increase diagnostic accuracy compared to the standard DWI protocol.

Diffusion imaging parameters enable a quantitative assessment of water diffusion behavior in the brain. However, the water diffusion probability distribution is influenced by diffusion barriers. Thus, ADC from DWI, as well as MK and MD from DKI, may reflect a tissue's heterogeneity, complexity, and micro-structure [24,25].

In the literature, IDH-mut astrocytic gliomas with a more homogeneous and looser cell composition show lower MK and higher MD and ADC values than IDH-wt gliomas with increased MK and decreased ADC and MD values due to increased cellularity, cellular heterogeneity, hemorrhage, necrosis, and microvascular proliferation [11,26]. 1p/19q-Codel Oligodendrogliomas also have higher MK and lower ADC and MD values than IDH-mut astrocytic gliomas because of their higher tumor cellularity and mitotic activity [11].

Our results may underline the hypothesis that different molecular glioma subtypes seem to show differences in diffusion-weighted MR-imaging. Specifically, higher b-values presented higher significance levels and might lead to better results in differentiating the three molecular glioma groups. Subsequently, a high b-value DWI could be a promising step towards non-invasive pre-interventional classification. In contrast, other publications 
clarified that distinction based on pre-interventional low b-value diffusion-weighted MRimaging into the molecular subgroups might also be applicable [27].

However, the differences between the three tumor subgroups are statistically significant, and the overlapping presents a considerable limitation for clinical use or decision making.

Higher $b$-values demonstrated higher diagnostic accuracy but were not sufficiently evaluated in this context [28]. As, in this study, $p$-values improved with higher b-values, further research is needed to assess the potential of ultra-high b-values up to $5000 \mathrm{~s} / \mathrm{mm}^{2}$ in distinguishing different types of gliomas. Looking at the high $b$-values, the acquisition becomes very time-consuming, as many averages or measured directions are required to get an acceptable signal-to-noise ratio, making the protocol more vulnerable to movement artifacts. ADC maps in this study only required two b-values instead of the six needed for DKI and led to comparable results. This reduction in the acquisition time by $66 \%$, while showing comparable results, has a higher chance of being implemented in a routine clinical workflow.

The post-processing for ADC measurements is more straightforward than DKI, as most scanners provide ADC calculations by default. Previous studies demonstrated that DWI-based glioma classification into the two groups of high-grade (HGG) and low-grade glioma (LGG) was possible with a sensitivity of over $90 \%$ [6,29]. Unfortunately, most of these reports have a relatively small patient cohort [30]. In addition, the molecular tumor stratification, used in the present article, correlates better with the clinical outcome than the outdated 2007 CNS WHO classification in HGG and LGG, used by most other research groups, and subsequently enables support of the clinical decision-making process [6,7,29].

As performed in the present study, classification into molecular glioma subtypes has become an integral part of the current 2016 CNS WHO due to its prognostic importance [17-19]. Previous studies focusing on the differentiation between HGG and LGG do not consider these clinically and prognostically relevant features in glioma. As recent research focuses on monitoring patients post-interventionally via DWI and distinguishing recurrent glioma from pseudoprogression, the performance of ADC-based evaluation strategies in this context has great potential but needs further investigation [31].

The estimates from DWI and DKI are biased by micro-capillary perfusion through the intravoxel incoherent motion (IVIM) effect, especially in lower b-values from 0 to $300 \mathrm{~s} / \mathrm{mm}^{2}[25,32,33]$. However, the perfusion-based influence in DWI and DKI needs to be considered in differentiating glioma subtypes. $\mathrm{B}_{500} \mathrm{ADC}$ maps showed better results than the $\mathrm{B}_{0} \mathrm{ADC}$ maps, which may be explained by the perfusion influence described to impair DWI at lower b-values [10,34,35]. Different types of perfusion imaging, such as arterial spin labeling and dynamic contrast-enhanced perfusion, have been described in recent studies as a potential approach to grading and determining IDH-mutation status [21,36]. Comparing the different evaluation strategies in this study, the results provided slightly higher levels of significance in the kurtosis-based evaluation. The differences in the average values showed better significance levels between the three tumor groups than the two b-value-dependent ADC-based methods. This confirms the results of previous studies [11].

However, ADC-based results remained comparable despite the acquisition time for DKI being three times longer and, therefore, the evaluation includes three times more data than the ADC-based approach. The MD results were not better than those of the ADC maps and required the same acquisition time as the DKI.

\section{Limitations}

This study is limited by its retrospective study design and different tumor locations. Additionally, the process of VOI delineation may have been subject to sampling bias because glioma infiltration may extend beyond $\mathrm{T} 2$ signal abnormalities [37,38]. The manual delineation of tumor volumes may risk possible bias, which could be reduced by automatic segmentation algorithms. However, studies have shown that the difference in tumor delimitation among different observers has a minor impact regarding the large number of voxels included in the histogram analysis $[39,40]$. There is potential bias regarding the relatively small numbers of patients with $\mathrm{IDH}_{\text {mut }}$ astrocytoma $\mathrm{WHO}$ grade 4 and 
$\mathrm{IDH}_{\mathrm{wt}}$ AS2 (early precursor lesion of $\mathrm{IDH}_{\mathrm{wt}} \mathrm{GBM}$ ). However, these numbers represent their natural incidence [17-20,41].

\section{Conclusions}

High-b-value ADC from preoperative DWI may be used to stratify molecular glioma subgroups and save time compared to DKI. Higher b-values of up to $2500 \mathrm{~s} / \mathrm{mm}^{2}$ may increase diagnostic accuracy compared to the standard DWI protocol.

Author Contributions: Conceptualization, U.K., U.E. and J.-M.H.; methodology, U.K. and J.-M.H.; software, U.K.; validation, N.C.N. and J.-M.H.; formal analysis, N.C.N., J.-M.H. and J.S.; investigation, N.C.N., S.C.V. and J.S.; resources, F.B., G.T. and J.S.; data curation, N.C.N. and S.C.V.; writing—original draft preparation, N.C.N. and J.-M.H.; writing-review and editing, F.B., G.T., S.C.V., J.S. and U.E.; visualization, N.C.N.; supervision, U.E. and U.K.; project administration, U.K. and J.-M.H.; funding acquisition, N.C.N. and J.S. All authors have read and agreed to the published version of the manuscript.

Funding: N.C.N. was supported by Deutsche Forschungsgemeinschaft (DFG) and Open Access Publishing Fund of the University of Tübingen.

Institutional Review Board Statement: The study was conducted according to the guidelines of the Declaration of Helsinki and approved by the Institutional Review Board of University Hospital Tübingen (Ref. No. 727/2017BO2 from 13 November 2017).

Informed Consent Statement: Written patient consent was waived due to retrospective study design.

Data Availability Statement: All data related to this study can be provided by the authors upon request.

Acknowledgments: N.C.N. was supported by the doctoral scholarship IZKF by the medical faculty of Tuebingen.

Conflicts of Interest: G.T. has served on advisory boards of AbbVie, Bayer and BMS; received consulting fees from AbbVie, Bayer; received speaker fees from Medac and Novocure; received travel grants from Novocure, Medac and BMS; received research grants from Roche Diagnostics and Medac. The other authors declare no conflict of interest. The funders had no role in the study's design, in the collection, analyses, or interpretation of data, in the writing of the manuscript, or in the decision to publish the results.

\section{Appendix A}

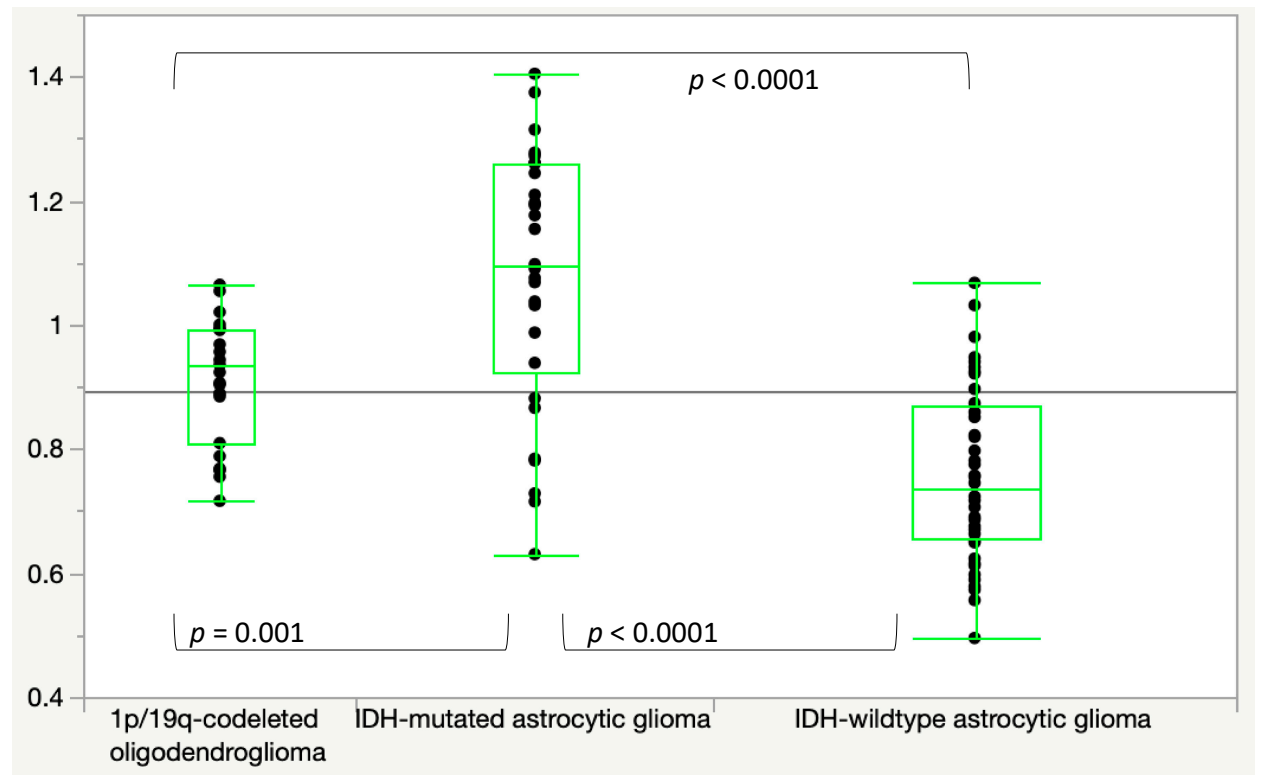

Figure A1. Distribution of the average ADC values using b-values of $500 \mathrm{~s} / \mathrm{mm}^{2}$ and $2500 \mathrm{~s} / \mathrm{mm}^{2}$, classified into the three molecular glioma groups: ADC, apparent diffusion coefficient. 


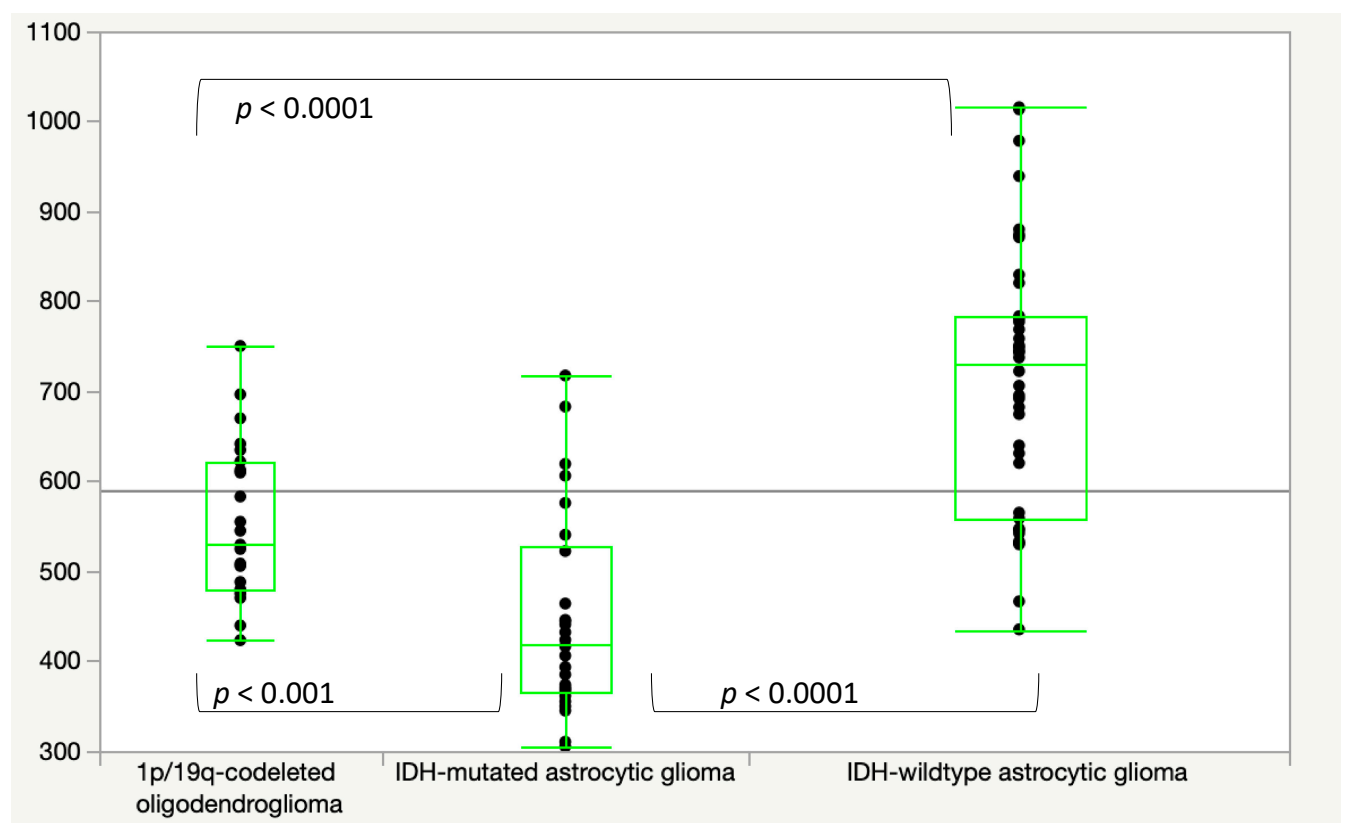

Figure A2. Distribution of the mean kurtosis values using all measured $\mathrm{b}$ values from $0 \mathrm{~s} / \mathrm{mm}^{2}$ to $2500 \mathrm{~s} / \mathrm{mm}^{2}$, classified into the three molecular glioma groups.

\section{References}

1. Schwartzbaum, J.A.; Fisher, J.L.; Aldape, K.D.; Wrensch, M. Epidemiology and molecular pathology of glioma. Nat. Clin. Pract. Neurol. 2006, 2, 494-503. [CrossRef]

2. Weller, M.; van den Bent, M.; Tonn, J.C.; Stupp, R.; Preusser, M.; Cohen-Jonathan-Moyal, E.; Henriksson, R.; Le Rhun, E.; Balana, C.; Chinot, O.; et al. European Association for Neuro-Oncology (EANO) guideline on the diagnosis and treatment of adult astrocytic and oligodendroglial gliomas. Lancet Oncol. 2017, 18, e315-e329. [CrossRef]

3. Van Cauter, S.; De Keyzer, F.; Sima, D.M.; Sava, A.C.; D’Arco, F.; Veraart, J.; Peeters, R.R.; Leemans, A.; Van Gool, S.; Wilms, G.; et al. Integrating diffusion kurtosis imaging, dynamic susceptibility-weighted contrast-enhanced MRI, and short echo time chemical shift imaging for grading gliomas. Neuro Oncol. 2014, 16, 1010-1021. [CrossRef]

4. Louis, D.N.; Perry, A.; Reifenberger, G.; von Deimling, A.; Figarella-Branger, D.; Cavenee, W.K.; Ohgaki, H.; Wiestler, O.D.; Kleihues, P.; Ellison, D.W. The 2016 World Health Organization Classification of Tumors of the Central Nervous System: A summary. Acta Neuropathol. 2016, 131, 803-820. [CrossRef] [PubMed]

5. Hempel, J.M.; Brendle, C.; Bender, B.; Bier, G.; Skardelly, M.; Gepfner-Tuma, I.; Eckert, F.; Ernemann, U.; Schittenhelm, J. Contrast enhancement predicting survival in integrated molecular subtypes of diffuse glioma: An observational cohort study. J. Neurooncol. 2018, 139, 373-381. [CrossRef] [PubMed]

6. Zhang, L.; Min, Z.; Tang, M.; Chen, S.; Lei, X.; Zhang, X. The utility of diffusion MRI with quantitative ADC measurements for differentiating high-grade from low-grade cerebral gliomas: Evidence from a meta-analysis. J. Neurol. Sci. 2017, 375, 103-106. [CrossRef] [PubMed]

7. Kang, Y.; Choi, S.H.; Kim, Y.J.; Kim, K.G.; Sohn, C.H.; Kim, J.H.; Yun, T.J.; Chang, K.H. Gliomas: Histogram analysis of apparent diffusion coefficient maps with standard- or high-b-value diffusion-weighted MR imaging-Correlation with tumor grade. Radiology 2011, 261, 882-890. [CrossRef] [PubMed]

8. Ellingson, B.M.; Bendszus, M.; Boxerman, J.; Barboriak, D.; Erickson, B.J.; Smits, M.; Nelson, S.J.; Gerstner, E.; Alexander, B.; Goldmacher, G.; et al. Consensus recommendations for a standardized Brain Tumor Imaging Protocol in clinical trials. Neuro Oncol. 2015, 17, 1188-1198.

9. Thust, S.C.; Heiland, S.; Falini, A.; Jager, H.R.; Waldman, A.D.; Sundgren, P.C.; Godi, C.; Katsaros, V.K.; Ramos, A.; Bargallo, N.; et al. Glioma imaging in Europe: A survey of 220 centres and recommendations for best clinical practice. Eur. Radiol. 2018, 28, 3306-3317. [CrossRef]

10. Hempel, J.M.; Schittenhelm, J.; Brendle, C.; Bender, B.; Bier, G.; Skardelly, M.; Tabatabai, G.; Castaneda Vega, S.; Ernemann, U.; Klose, U. Effect of Perfusion on Diffusion Kurtosis Imaging Estimates for In Vivo Assessment of Integrated 2016 WHO Glioma Grades: A Cross-Sectional Observational Study. Clin. Neuroradiol. 2017, 28, 481-491. [CrossRef]

11. Hempel, J.M.; Bisdas, S.; Schittenhelm, J.; Brendle, C.; Bender, B.; Wassmann, H.; Skardelly, M.; Tabatabai, G.; Vega, S.C.; Ernemann, U.; et al. Erratum to: In vivo molecular profiling of human glioma using diffusion kurtosis imaging. J. Neurooncol. 2017, 131, 103. [CrossRef] [PubMed] 
12. Hempel, J.M.; Brendle, C.; Bender, B.; Bier, G.; Kraus, M.S.; Skardelly, M.; Richter, H.; Eckert, F.; Schittenhelm, J.; Ernemann, U.; et al. Diffusion kurtosis imaging histogram parameter metrics predicting survival in integrated molecular subtypes of diffuse glioma: An observational cohort study. Eur. J. Radiol. 2019, 112, 144-152. [CrossRef] [PubMed]

13. Capper, D.; Weissert, S.; Balss, J.; Habel, A.; Meyer, J.; Jager, D.; Ackermann, U.; Tessmer, C.; Korshunov, A.; Zentgraf, H.; et al. Characterization of R132H mutation-specific IDH1 antibody binding in brain tumors. Brain Pathol. 2010, 20, 245-254. [CrossRef] [PubMed]

14. Hartmann, C.; Meyer, J.; Balss, J.; Capper, D.; Mueller, W.; Christians, A.; Felsberg, J.; Wolter, M.; Mawrin, C.; Wick, W.; et al. Type and frequency of IDH1 and IDH2 mutations are related to astrocytic and oligodendroglial differentiation and age: A study of 1010 diffuse gliomas. Acta Neuropathol. 2009, 118, 469-474. [CrossRef]

15. Ebrahimi, A.; Skardelly, M.; Bonzheim, I.; Ott, I.; Muhleisen, H.; Eckert, F.; Tabatabai, G.; Schittenhelm, J. ATRX immunostaining predicts IDH and H3F3A status in gliomas. Acta Neuropathol. Commun. 2016, 4, 60. [CrossRef]

16. Thon, N.; Eigenbrod, S.; Grasbon-Frodl, E.M.; Ruiter, M.; Mehrkens, J.H.; Kreth, S.; Tonn, J.C.; Kretzschmar, H.A.; Kreth, F.W. Novel molecular stereotactic biopsy procedures reveal intratumoral homogeneity of loss of heterozygosity of $1 \mathrm{p} / 19 \mathrm{q}$ and TP53 mutations in World Health Organization grade II gliomas. J. Neuropathol. Exp. Neurol. 2009, 68, 1219-1228. [CrossRef]

17. Reuss, D.E.; Sahm, F.; Schrimpf, D.; Wiestler, B.; Capper, D.; Koelsche, C.; Schweizer, L.; Korshunov, A.; Jones, D.T.; Hovestadt, V.; et al. ATRX and IDH1-R132H immunohistochemistry with subsequent copy number analysis and IDH sequencing as a basis for an "integrated" diagnostic approach for adult astrocytoma, oligodendroglioma and glioblastoma. Acta Neuropathol. 2015, 129, 133-146. [CrossRef] [PubMed]

18. Reuss, D.E.; Mamatjan, Y.; Schrimpf, D.; Capper, D.; Hovestadt, V.; Kratz, A.; Sahm, F.; Koelsche, C.; Korshunov, A.; Olar, A.; et al. IDH mutant diffuse and anaplastic astrocytomas have similar age at presentation and little difference in survival: A grading problem for WHO. Acta Neuropathol. 2015, 129, 867-873. [CrossRef]

19. Reuss, D.E.; Kratz, A.; Sahm, F.; Capper, D.; Schrimpf, D.; Koelsche, C.; Hovestadt, V.; Bewerunge-Hudler, M.; Jones, D.T.; Schittenhelm, J.; et al. Adult IDH wild type astrocytomas biologically and clinically resolve into other tumor entities. Acta Neuropathol. 2015, 130, 407-417. [CrossRef]

20. Suzuki, H.; Aoki, K.; Chiba, K.; Sato, Y.; Shiozawa, Y.; Shiraishi, Y.; Shimamura, T.; Niida, A.; Motomura, K.; Ohka, F.; et al. Mutational landscape and clonal architecture in grade II and III gliomas. Nat. Genet. 2015, 47, 458-468. [CrossRef]

21. Brendle, C.; Hempel, J.M.; Schittenhelm, J.; Skardelly, M.; Tabatabai, G.; Bender, B.; Ernemann, U.; Klose, U. Glioma Grading and Determination of IDH Mutation Status and ATRX loss by DCE and ASL Perfusion. Clin. Neuroradiol. 2017, 28, 421-428. [CrossRef] [PubMed]

22. Hempel, J.M.; Schittenhelm, J.; Brendle, C.; Bender, B.; Bier, G.; Skardelly, M.; Tabatabai, G.; Castaneda Vega, S.; Ernemann, U.; Klose, U. Histogram analysis of diffusion kurtosis imaging estimates for in vivo assessment of 2016 WHO glioma grades: A cross-sectional observational study. Eur. J. Radiol. 2017, 95, 202-211. [CrossRef] [PubMed]

23. Hempel, J.M.; Schittenhelm, J.; Bisdas, S.; Brendle, C.; Bender, B.; Bier, G.; Skardelly, M.; Tabatabai, G.; Castaneda Vega, S.; Ernemann, U.; et al. In vivo assessment of tumor heterogeneity in WHO 2016 glioma grades using diffusion kurtosis imaging: Diagnostic performance and improvement of feasibility in routine clinical practice. J. Neuroradiol. 2018, 45, 32-40. [CrossRef]

24. Pekmezci, M.; Rice, T.; Molinaro, A.M.; Walsh, K.M.; Decker, P.A.; Hansen, H.; Sicotte, H.; Kollmeyer, T.M.; McCoy, L.S.; Sarkar, G.; et al. Adult infiltrating gliomas with WHO 2016 integrated diagnosis: Additional prognostic roles of ATRX and TERT. Acta Neuropathol. 2017, 133, 1001-1016. [CrossRef] [PubMed]

25. Le Bihan, D.; Breton, E.; Lallemand, D.; Aubin, M.L.; Vignaud, J.; Laval-Jeantet, M. Separation of diffusion and perfusion in intravoxel incoherent motion MR imaging. Radiology 1988, 168, 497-505. [CrossRef]

26. Popov, S.; Jury, A.; Laxton, R.; Doey, L.; Kandasamy, N.; Al-Sarraj, S.; Jurgensmeier, J.M.; Jones, C. IDH1-associated primary glioblastoma in young adults displays differential patterns of tumour and vascular morphology. PLoS ONE 2013, 8, e56328. [CrossRef]

27. Leu, K.; Ott, G.A.; Lai, A.; Nghiemphu, P.L.; Pope, W.B.; Yong, W.H.; Liau, L.M.; Cloughesy, T.F.; Ellingson, B.M. Perfusion and diffusion MRI signatures in histologic and genetic subtypes of WHO grade II-III diffuse gliomas. J. Neurooncol. 2017, 134, 177-188. [CrossRef] [PubMed]

28. Han, H.; Han, C.; Wu, X.; Zhong, S.; Zhuang, X.; Tan, G.; Wu, H. Preoperative grading of supratentorial nonenhancing gliomas by high b-value diffusion-weighted 3 T magnetic resonance imaging. J. Neurooncol. 2017, 133, 147-154. [CrossRef]

29. Shan, W.; Wang, X.L. Clinical application value of 3.0T MR diffusion tensor imaging in grade diagnosis of gliomas. Oncol. Lett. 2017, 14, 2009-2014. [CrossRef] [PubMed]

30. Aggarwal, A.; Das, P.K.; Shukla, A.; Parashar, S.; Choudhary, M.; Kumar, A.; Kumar, N.; Dutta, S. Role of Multivoxel Intermediate TE 2D CSI MR Spectroscopy and 2D Echoplanar Diffusion Imaging in Grading of Primary Glial Brain Tumours. J. Clin. Diagn. Res. 2017, 11, TC05-TC08. [CrossRef] [PubMed]

31. Yu, Y.; Ma, Y.; Sun, M.; Jiang, W.; Yuan, T.; Tong, D. Meta-analysis of the diagnostic performance of diffusion magnetic resonance imaging with apparent diffusion coefficient measurements for differentiating glioma recurrence from pseudoprogression. Medicine 2020, 99, e20270. [CrossRef]

32. Jensen, J.H.; Helpern, J.A. MRI quantification of non-Gaussian water diffusion by kurtosis analysis. NMR Biomed. 2010, 23, 698-710. [CrossRef] [PubMed] 
33. De Luca, A.; Bertoldo, A.; Froeling, M. Effects of perfusion on DTI and DKI estimates in the skeletal muscle. Magn. Reson. Med. 2017, 78, 233-246. [CrossRef]

34. Yamada, I.; Aung, W.; Himeno, Y.; Nakagawa, T.; Shibuya, H. Diffusion coefficients in abdominal organs and hepatic lesions: Evaluation with intravoxel incoherent motion echo-planar MR imaging. Radiology 1999, 210, 617-623. [CrossRef] [PubMed]

35. Freiman, M.; Voss, S.D.; Mulkern, R.V.; Perez-Rossello, J.M.; Callahan, M.J.; Warfield, S.K. In vivo assessment of optimal b-value range for perfusion-insensitive apparent diffusion coefficient imaging. Med. Phys. 2012, 39, 4832-4839. [CrossRef]

36. Brendle, C.; Klose, U.; Hempel, J.M.; Schittenhelm, J.; Skardelly, M.; Tabatabai, G.; Ernemann, U.; Bender, B. Association of dynamic susceptibility magnetic resonance imaging at initial tumor diagnosis with the prognosis of different molecular glioma subtypes. Neurol. Sci. 2020, 41, 3625-3632. [CrossRef]

37. Price, S.J.; Jena, R.; Burnet, N.G.; Hutchinson, P.J.; Dean, A.F.; Pena, A.; Pickard, J.D.; Carpenter, T.A.; Gillard, J.H. Improved delineation of glioma margins and regions of infiltration with the use of diffusion tensor imaging: An image-guided biopsy study. AJNR Am. J. Neuroradiol. 2006, 27, 1969-1974. [PubMed]

38. Grier, J.T.; Batchelor, T. Low-grade gliomas in adults. Oncologist 2006, 11, 681-693. [CrossRef]

39. Emblem, K.E.; Nedregaard, B.; Nome, T.; Due-Tonnessen, P.; Hald, J.K.; Scheie, D.; Borota, O.C.; Cvancarova, M.; Bjornerud, A. Glioma grading by using histogram analysis of blood volume heterogeneity from MR-derived cerebral blood volume maps. Radiology 2008, 247, 808-817. [CrossRef]

40. Kim, H.; Choi, S.H.; Kim, J.H.; Ryoo, I.; Kim, S.C.; Yeom, J.A.; Shin, H.; Jung, S.C.; Lee, A.L.; Yun, T.J.; et al. Gliomas: Application of cumulative histogram analysis of normalized cerebral blood volume on 3 T MRI to tumor grading. PLoS ONE 2013, 8, e63462. [CrossRef]

41. Unruh, D.; Schwarze, S.R.; Khoury, L.; Thomas, C.; Wu, M.; Chen, L.; Chen, R.; Liu, Y.; Schwartz, M.A.; Amidei, C.; et al. Mutant IDH1 and thrombosis in gliomas. Acta Neuropathol. 2016, 132, 917-930. [CrossRef] [PubMed] 